\title{
The effect of different types of attachment system in implant assisted over denture on rate of resorption of grafted anterior mandible (prospective clinical study)
} Article

\author{
Noha Helmy Nawar and Heba Sleem ${ }^{b}$ \\ ${ }^{a}$ Department of Prosthodontic, ${ }^{b}$ Department of Oral and Maxillofacial Surgery, \\ Faculty of Dentistry, Ain Shams University, Cairo, Egypt
}

\begin{abstract}
Purpose: Mandibular implant assisted overdentures have been considered as satisfactory treatment plan of mandibular edentulism and might be hindered by limited bone height and or width in interforaminal region which necessitate implementation of bone grafts. However, bone graft resorption is expected after loading where the design of retention system could influence resorption rate. So the objective of this study is to assess the effect of using retention sil versus PEEK matrix as a retention system of overdenture on supporting bone of augmented anterior mandible.

Material and Methods: Fourteen patients were randomly assigned into two groups after being subjected to anterior mandibular bone grafting and implant insertion., for group I patients. Implants were loaded by mandibular overdentures using the OLS attachments system (PEEK female) and for group II implants were loaded using silicone matrix (Retention Sil 400) over the locator abutments with its dual retention mechanism. Implant stability was assessed using (osstell). Peri-implant bone loss was radiographically assessed after loading (at 6 months and 1 year intervals).

Results: There was no significant increase in implant stability between the two groups. However, group II presents significantly lower bone loss one year after loading $(p \leq 0.01)$ than group I.

Conclusion: It could be concluded that resilient matrix (retention sil) for locator attachment induce less bone resorption than peek matrix in anterior grafted mandibular bone.
\end{abstract}

Key Words: Bone graft, OLS attachment, Over denture, Retention sil.

Received: 04 May 2020, Accepted: 09 May 2020.

Corresponding Author: Heba Sleem, Department of Oral and Maxillofacial Surgery, Faculty of Dentistry, Ain Shams University, Cairo, Egypt, Tel.: +20225303020, Mobile:+201001942251, E-mail: drsleemh@gmail.com.

ISSN: 2090-097X, April 2020, Vol. 11, No. 2

\section{INTRODUCTION}

The increased demands of mandibular implant overdenture treatment, encouraged the clinician to consider it as the quality of standard care for the edentulous patients $^{[1,2]}$. However implant over denture may be hindered by deficient bone volume in the planned position. The available literature has mainly focused on ridge augmentation in the maxillary bone and few studies have been performed on the adequacy of these materials in bone grafts for augmentation of the mandible.

Autogenous bone was used for many decades in ridge augmentation procedures and still stated as the gold standard. Intra-oral sites have the advantage of similar structure, convenient access, as well use of one operative site. It shows less morbidity when compared to extra-oral graft sites which requires general anesthesia and skin incisions with use of two operative sites instead of one ${ }^{[3]}$. Unfortunately, limited volume of intra-oral graft sites hinders this option in many cases. A mixture of autologous and inorganic bovine bone covered with bio absorbable membranes is one of recommended techniques to overcome limited donor site volume (mainly in horizontal deficiency correction $)^{[4,5]}$. Rate of resorption of grafted bone is debatable point with many contributing factors including type of the graft, timing of implant insertion, anatomical site as well as prosthetic technique adopted ${ }^{[6]}$.

The choice of attachment system depends on the amount of retention needed, arch form (especially after being modified), patient expectation, cost, and load distribution to the implants and their surrounding tissue ${ }^{[7,8]}$.

The rehabilitation of the edentulous arch requires a certain amount of vertical space between the opposing arches to ensure adequate restorative material thickness, space for the retentive elements, esthetics, and cleansability. The required inter-arch space needed for an implantretained overdenture measured from the implant shoulder to the incisal edge is approximately 12 to $14 \mathrm{~mm}$. Two to 3 millimeters of soft tissue thickness is generally present above the implant ${ }^{[9]}$. It was often claimed that resilient retention mechanisms for overdenture stabilization should be used to distribute tissue and implant support ${ }^{[10]}$. 
In different height mucosa thicknesses, locator attachment distributed the load better in comparison to ball attachment of the implant and its surrounding tissue, whereas the ball attachment did not ${ }^{[11]}$.

Recently, Poly Ether Ether Ketone (PEEK) material was introduced as a great development in prosthetic and implant dentistry due to its good mechanical and physical properties. In comparison to metal,as it replaces metallic alloy in prosthetic dentistry as in bar attachment, as reinforcement of dentures , and as partial denture framework and used in manufacturing attachments. PEEK has shown acceptable flexibility with high mechanical resistance to wear and high tensile, fatigue and flexural strength. PEEK is used to produce high-quality plastic parts that are thermo-stable and both electrically and thermally insulating. It also possess low specific mass, elasticity similar to the one of bone and this property is the most beneficial one in prosthetic dentistry, and an almost non-existent material fatigue ${ }^{[12,13]}$.

When an attachment system with double retention setting is used, like the Locator, it is recommended to use soft acrylic or silicone material as matrices during osseointegration. In this regard, silicone materials with different retention levels were developed, such as Retention. Sil (Bredent) that has 3 options according to the detachment force desired $(200,400,600 \mathrm{gf})^{[14]}$.

So the purpose of this study is to assess the effect of using retention sil versus PEEK as matrix for locator attachment as a retention system of overdenture on supporting bone of augmented anterior mandible (deficient width).

\section{MATERIALS AND METHODS}

\section{Participants}

Fourteen edentulous patients indicated for implant supported mandibular over-denture were included in the study. Cases included from outpatient clinic of Prosthodontics Department, Faculty of Dentistry, Ain Shams University (2018 - 2020). Patients were clinically examined (age ranged between 50 and 65 years). Evaluation of implant potential sites and suitable size and length were performed using cone beam computerized tomography (CBCT). Cases included are those presented with horizontal ridge deficiency (thin wiry ridge 3 - $4 \mathrm{~mm}$ ).

After the patients were informed about the line of treatment and the need for frequent recalls throughout the total period of the research, they all signed a written consent. Patients were included in the study, provided that they fulfilled the following criteria: healthy mucosa, complete edentulism for at least 1 year and having defecient bone in proposed implant site. Exclusion criteria included one or more of the following conditions: diabetes, smoking, osteoporosis, immune deficiency, radiotherapy to the head and neck region and anticoagulant therapy.

\section{Patients grouping:}

Patients were admitted for bone grafting (autogenous alloplastic composite) and implant insertion then randomly assigned using random number generator and checker into (* www. psychicscience.org/random.aspx) two equal groups.

Group I: Implants were loaded by mandibular overdentures using the OLS attachments system ( PEEK female).

Group II: Implants were loaded using silicone matrix (Retention Sil 400) over the locator abutments.

\section{Surgical procedure:}

\section{A- Bone augmentation and Implant insertion:}

Bone augmentation procedure and implant insertion was performed under local anesthesia bilateral Inferior alveolar nerve block (IANB). Autologous bone was harvested from the same surgical site (alveolar bone) where full mucoperiosteum flap reflected extending from first molar region of one side to the first molar region of the other side with carful dissection of mental nerves. A prefabricated bone reduction template was secured in place using three pins; after that crestal part of alveolus was resected as preplanned using piezoelectric micro saw then the bone reduction template was removed. The resected bone milled using manual mill into small particles and mixed with bovine hydroxyapatite (bioss geistlich). Bone supported sterolithographic surgical guide fixed using 3 pins. Implant site drilling was performed using sequential drills with increasing diameters. The guide was used to place two parallel implants in interforaminal region of sizes 3.7 x $10 \mathrm{~mm}$ (Osteoseal dental implants, California, USA). Bone supported guide was removed and the graft mixer was used for ridge augmentation buccal around the placed implants. Finally a pericardium membrane (Jason membrane Botiss Company) was fixed using two tacs (to cover and protect the graft). Mucoperiosteum flap was carefully repositioned and sutured in place using $4(0)$ vicryl Figure (1). Post-operative medications including antibiotic and analgesics were prescribed as well as oral hygiene measure instructions. 

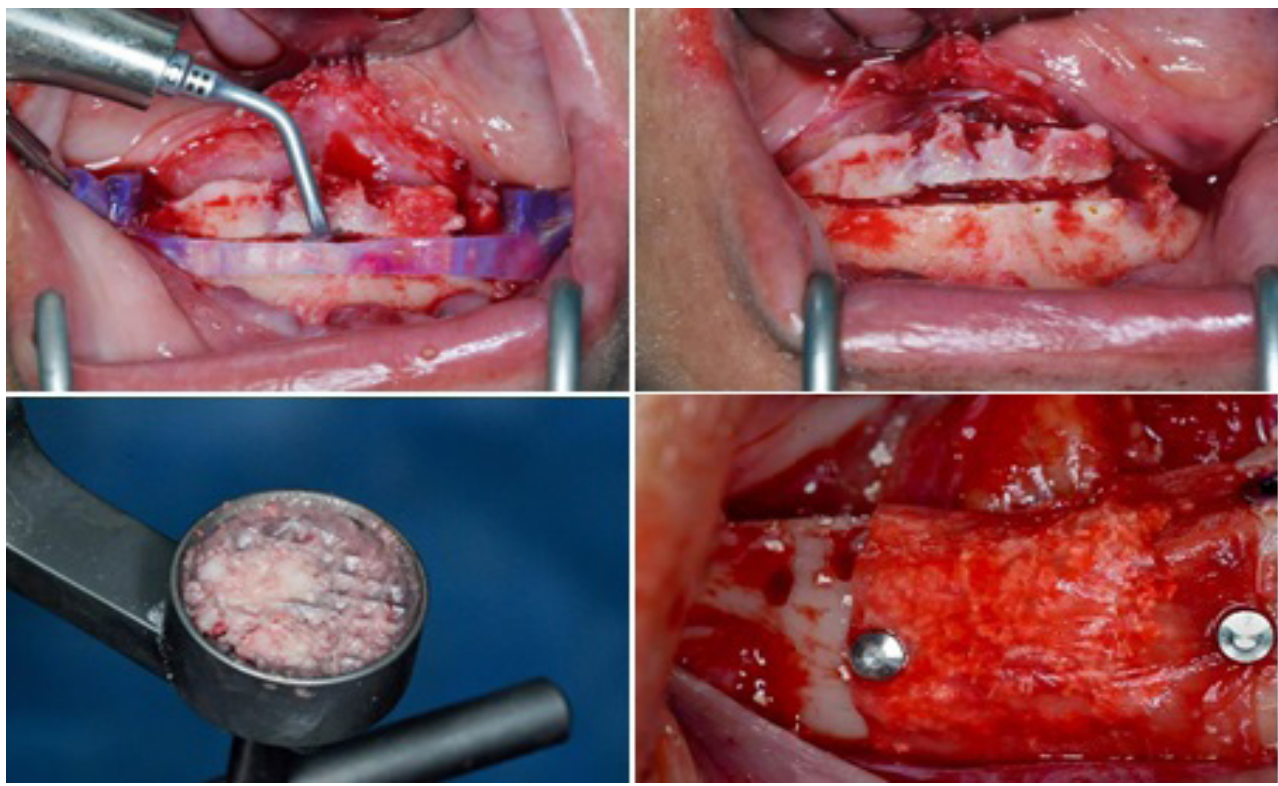

Figure 1: Upper left, flap reflected and bone reduction template secured. Upper right, crestal bone resected using piezoelectric micro saw. Lower left, the resected bone milled and mixed with bovine hydroxyapatite. Lower right, the graft mixer was used for ridge augmentation and a pericardium membrane was fixed using two tacs.

\section{Prosthetic procedures:}

After 6 months, to assure graft consolidation and implant Osseo integration, removal of cover screws were done and placement of smart peg for assessment of stability was done using osstell (Figure 2). All patients first received new complete conventional dentures constructed with bilateral balanced occlusal scheme and allowed to wear it 2 weeks before second stage of surgery (implant uncoverage) and attachment of locator.

Recesses were prepared in the fitting surface of the new mandibular denture. For group I: the metal housings with the peek matrix inside were picked up intraorally under occluding force to the fitting surface of mandibular denture with duralay . After the duralay was cured, the denture was removed and the processing inserts were discarded. The excess acrylic was removed, and the denture was polished before changing to the final retention insert. The patients were prescribed a soft diet. After this period, they were asked not to brush the operated areas and to rinse instead with $0-12 \%$ chlorhexidine mouthwash three times per day for 14 days. At the post-operative visits, occlusion was checked as well as the need for any prosthetic adjustments (Figure 3).

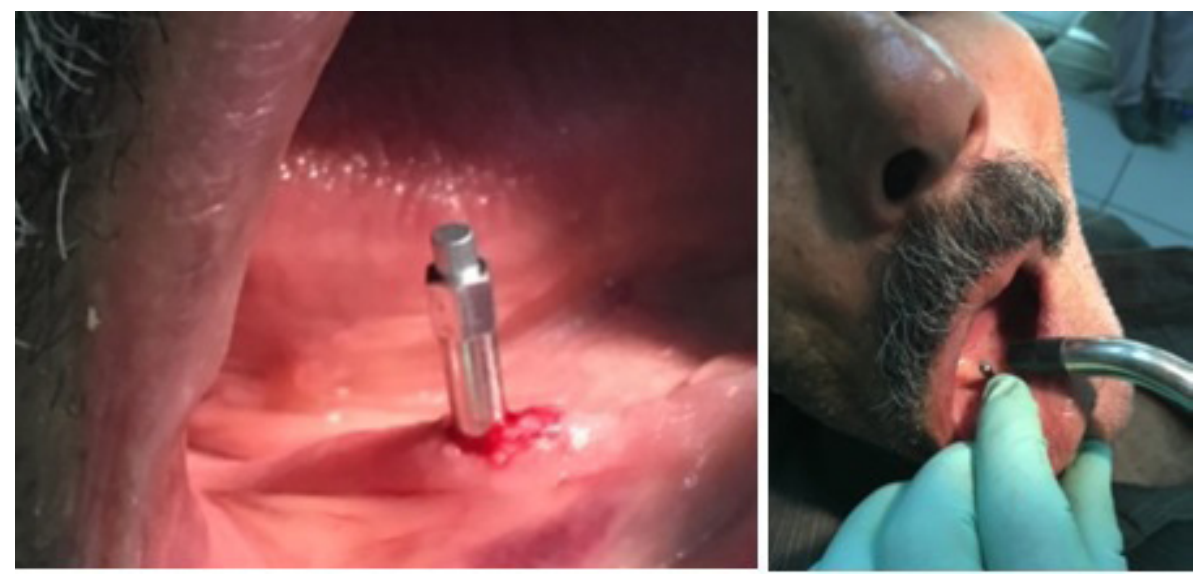

Figure 2: Attaching smart peg and using osstell to measure implant stability. 


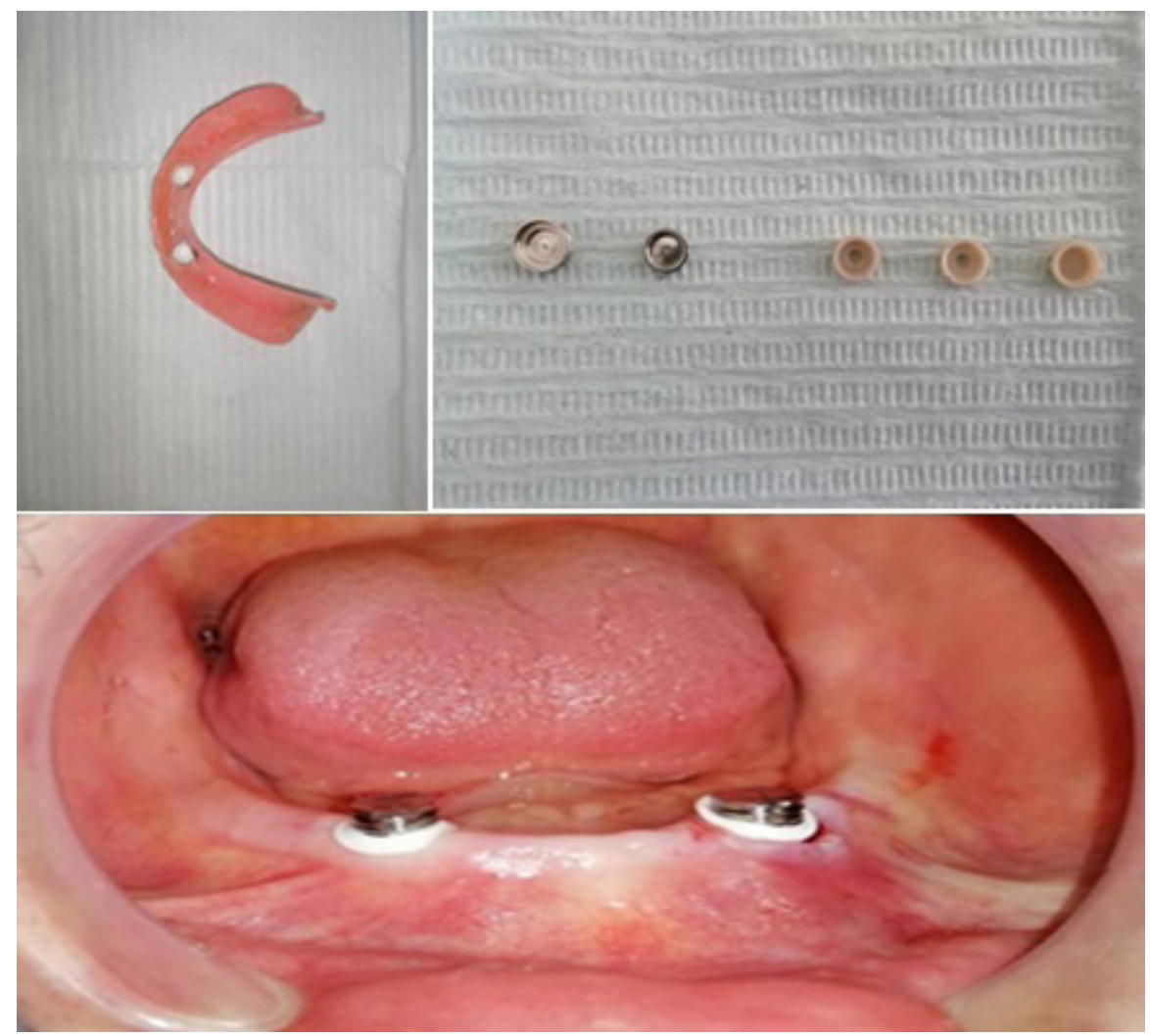

Figure 3: Picking up of ols attachments.

For group II retention -sil was used which is silicone with very high tensile strength, it is perfectly suited to ensure a resilient position of the denture; and a good guidance of the denture. Then the recess prepared opposite to the implant was filled with retention-sil. This combination provides high level of patient comfort while eating and chewing and avoids changes to the position of the denture. After the prepared recess in the denture was conditioned with Multi-Sil liquid, retention sil (Bredent medical Germany) is filled up to the top and seated in the patient mouth under occluding force, after the material sitting the denture was removed and the excess was trimmed. As per the manufacture instruction, the retention sil is a silicone matrix so the whole denture should be relined to prevent fulcrum action around the two implant, while in group I the pick up was done using duralay which after setting has no resiliency, the same as the fitting surface of the whole denture. In the current study we aimed to compare the effect of 2 anchoraging systems on the graft survivability (Figure 4).

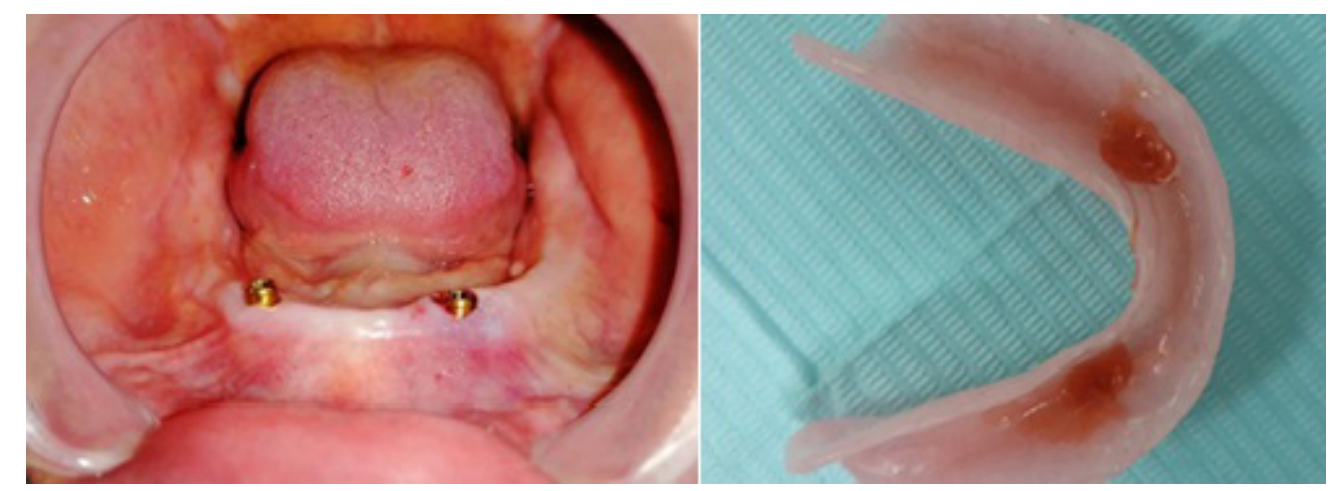

Figure 4: Retention sil is used as a matrix for locator. 


\section{Follow-up and assessment:}

All patients were clinically assessed at regular follow up intervals (every 3 months). Follow-up included in a plaque control protocol, checking occlusion as well as the need for any prosthetic adjustments. Implant stability was assessed during the second phase of surgery and six months post-loading using resonance frequency analysis (osstell). A cone beam computed tomography (CBCT) was conducted for each patient on the mandible (while wearing the denture) at the time of loading ( 6 months after the grafting), six months and 12 months of loading. Each patient was seated on the machine chair in an upright position with his back rested against the backrest.

Marginal bone height change around the implants was evaluated using the linear measurement software system supplied with the $\mathrm{CBCT}$ radiographs. The bone height was measured by measuring the distance from the alveolar crest to the implant apex. Two horizontal lines one at the alveolar bone crest and the other at the implant apex were drawn; the software then automatically gives the amount of linear measurements in millimeters on the screen between the two lines. Then the difference in bone height was calculated by subtraction. This was done on the four surfaces (labial, lingual, mesial and distal) and average was taken (Figure 5).

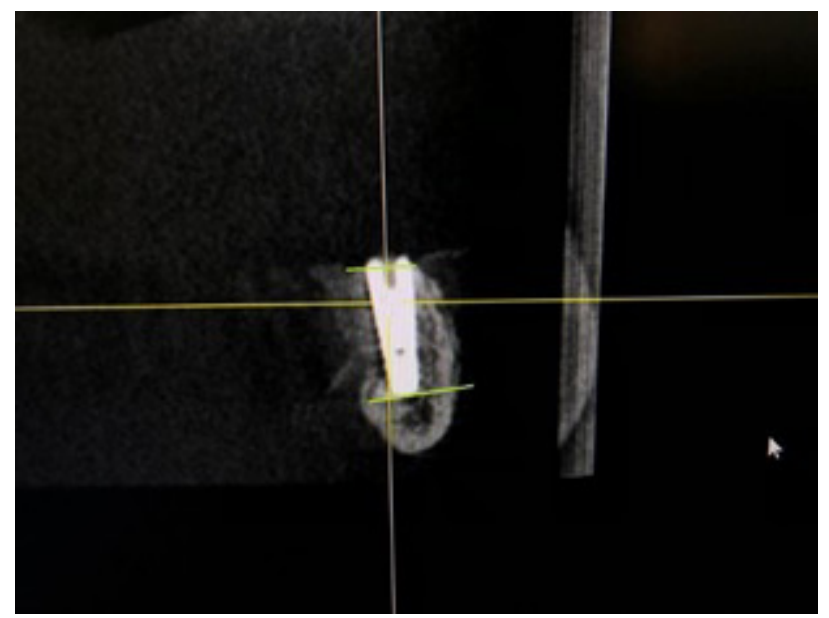

Figure 5: CBCT of case no 1 (six months post-operative) used for assessment of crestal bone loss. The bone height was measured by measuring the distance from the alveolar crest to the implant apex. Two horizontal lines one at the alveolar bone crest and the other at the implant apex were drawn.

\section{Statistical methodology:}

Collected data tabulated and analyzed including stability measurements and alveolar bone loss. Statistical analysis was performed by Microsoft Office 2013 (Excel) and Statistical Package for Social Science (SPSS) version 20. The significant level was set at $\mathrm{P} \leq 0.05$. Kolmogorov-Smirnova and Shapiro-Wilk tests were used to assess data normality. Data were assumed normally distributed. Independent t-test was done to test significance of difference in bone loss around the two implants. Paired T-test was used to assess the effect of time.

\section{RESULTS}

A total of 28 implants have been placed in fourteen patients. All patients recovered surgical procedure without major complications. Mean bone graft volume $(2+/-0.5 \mathrm{cc})$. At the loading time $(6$ months postoperative) Implant stability was $(55.57+/-8.2)$ in group I which significantly increased six months after loading (73.43) (Table 1). Stability at loading time in group II was $(62+/-7.3)$ which signifacntly increased after six months of loading (75.29) (Table 2). The increase in implant stability after six months of loading was higher in group I however, this difference was statistically insignificant (Table 3).

Table 1: Comparison between Osstell (ISQ) readings during follow-up period among group I:

\begin{tabular}{lllllll}
\hline $\begin{array}{l}\text { Follow-up } \\
\text { periods }\end{array}$ & $\mathrm{N}$ & Mean & $\mathrm{SD}$ & $\mathrm{t}$ stat & $\mathrm{p}$-value & Significance \\
\hline $\begin{array}{l}6 \text { months post- } \\
\text { operative }\end{array}$ & 7 & 55.57 & 8.02 & & & \\
$\begin{array}{l}6 \text { months post- } \\
\text { loading }\end{array}$ & 73.43 & 6.74 & 9.55 & $\leq 0.01$ & HS \\
\hline
\end{tabular}

Table 2: Comparison between Osstell (ISQ) readings during follow-up period among group II:

\begin{tabular}{lllllll}
\hline $\begin{array}{l}\text { Follow-up } \\
\text { periods }\end{array}$ & $\mathrm{N}$ & Mean & $\mathrm{SD}$ & $\mathrm{t}$ stat & $\mathrm{p}$-value & Significance \\
\hline $\begin{array}{l}6 \text { months post- } \\
\text { operative }\end{array}$ & 7 & 62 & 7.37 & & & \\
$\begin{array}{l}6 \text { months post- } \\
\text { loading }\end{array}$ & 7 & 75.29 & 7.36 & 6.39 & $\leq 0.01$ & HS \\
\hline
\end{tabular}

Table 3: Comparison between group I and group II regarding change in Osstell (ISQ) readings along follow-up period:

\begin{tabular}{llllccc}
\hline Group & $\mathrm{N}$ & Mean & $\mathrm{SD}$ & t-state & P value & Significance \\
\hline Group I & 7 & 17.8 & 4.5 & & & \\
Group II & 7 & 13.2 & 5.3 & & & NS \\
\hline
\end{tabular}

\section{Bone height measurements:}

\section{Bone loss in the first six months:}

Upon comparing crestal bone loss around implants between groups results reveals comparable nonsignificant bone loss around implant in the first six months (Table 4). 
Table 4: Comparison between group I and group II regarding change in bone height in the first six months of the follow-up period:

\begin{tabular}{llllllc}
\hline Group & N & Mean & SD & t-state & P value & Significance \\
\hline Group I & 7 & 0.414 & 0.11 & & & \\
Group II & 7 & 0.36 & 0.09 & 0.86 & $>0.05$ & NS \\
\hline
\end{tabular}

\section{Bone loss after one year of implant loading:}

\section{Group I:}

Upon comparing crestal bone loss around implants in group I as measured at loading time $(0.414+/-0.1)$ with bone loss one year after loading $(0.89+/-0.12)$, there was significant difference Table (5).

Table 5: Comparison between the change in bone height in the first 6 months and one year after implant loading among group I:

\begin{tabular}{lllllll}
\hline $\begin{array}{l}\text { F o 1 l o w - u p } \\
\text { periods }\end{array}$ & $\mathrm{N}$ & Mean & $\mathrm{SD}$ & t-state & P value & Significance \\
\hline $\begin{array}{l}\text { Bone loss till } 6 \mathrm{~m} \\
\text { post-operative }\end{array}$ & 7 & 0.414 & & & & \\
$\begin{array}{l}\text { Bone loss till one } \\
\text { year after loading }\end{array}$ & 7 & 0.89 & 11.01 & $\leq 0.01$ & HS \\
\hline
\end{tabular}

\section{Group II:}

When comparing crestal bone loss around implants in group II at loading time $(0.36+/-0.09)$ with bone loss one year after loading $(0.65+/-0.1)$, there was significant difference Table (6).

Table 6: Comparison between the change in bone height till 6 months and one year after implant loading among group II:

\begin{tabular}{lllllll}
\hline $\begin{array}{l}\text { Follow-up } \\
\text { periods }\end{array}$ & $\mathrm{N}$ & Mean & $\mathrm{SD}$ & t-state & $\mathrm{P}$ value & Significance \\
\hline $\begin{array}{l}\text { Bone loss } \\
\text { till } 6 \mathrm{~m} \text { post- }\end{array}$ & 0.36 & 0.09 & & & \\
$\begin{array}{l}\text { operative } \\
\begin{array}{l}\text { Bone loss till } 7 \\
\text { one year after } \\
\text { loading }\end{array}\end{array}$ & 0.65 & 0.11 & 6.6 & $\leq 0.01$ & HS \\
\hline
\end{tabular}

\section{Comparison between the 2 groups:}

Amount of bone loss after loading one year after implant loading was significantly greater in group I cases than group II (Table 7).
Table 7: Comparison between group I and group II regarding change in bone height in the next six months of the follow-up period:

\begin{tabular}{llllccc}
\hline Group & $\mathrm{N}$ & Mean & SD & t-state & P value & Significance \\
\hline Group I & 7 & 0.475 & 0.1 & \multirow{2}{*}{3.2} & $\leq 0.01$ & HS \\
Group II & 7 & 0.28 & 0.2 & & & \\
\hline
\end{tabular}

\section{DISCUSSION}

Mandibular implant-supported over denture is highly predictable technique with significant improvement of quality of life in elderly patient. However many factors should be considered to increase survival rates. Quantity and quality of bone foundation, surgical technique, type, number and size of selected implant as well as prosthetic protocol are very crucial factors in such cases ${ }^{[15]}$.

Correction of ridge deficiency with different grafting techniques enhances success of dental implant. Intra oral bone grafts (chin, ramus or alveolar) are very good choice with less trauma, better healing and lake of scars. The autogenous particulate alloplastic composite used in the present study is predictable technique, it compensates for limited intra-oral graft volume. However it is indicated for horizontal augmentation of narrow ridges only and should be protected with membranes ${ }^{[16]}$.

The alternative treatment option of wiry ridge is ridge plateauing, however it is not suitable if the ridge is narrow at the basal part. Also, it decreases bone height and increase inter arch space. Implant placed simultaneous with bone augmentation procedure which favors graft healing, implant Osseo integration and shorten treatment time $^{[17]}$. Use of four implants to support over denture would provide more support and retention however; more coast and positional difficulty would be encountered ${ }^{[18]}$.

The anchorage design system might affect the survival rate of the graft and supporting bone in general because implant loading is dependent on the anchorage system used $^{[19]}$.The locator attachment offers great clinical results with respect to oral hygiene parameters and the frequency of prosthodontic maintenance $\mathrm{e}^{[20,21]}$.

In vitro studies have concluded that attachment type and design have an influence on the amount of stresses transferred to the implants and peri-implant bone, so the dual retention property of locator attachment which comes from friction between the inner and outer surface together with limited lateral and hinge movement ${ }^{[22]}$ may be responsible for transferring more moment loads to the implant, thus contributing to increased bone loss. In line with this explanation, Celik and Uludag ${ }^{[23]}$ noted greater peri-implant stresses with Locator when compared to ball 
and bar attachments used for three implants supporting mandibular over denture.

They attributed the increased stresses to the matrixpatrix relationship of the attachment which becomes more dominant for inclined than vertical implant arrangement which might account for the result in group I even with peek matrix. When an attachment system with increased retention is used, like the Locator, it is recommended to use soft acrylic or silicone material as matrices during Osseo integration. In this regard, silicone materials with different retention levels were developed, such as Retention.Sil (Bredent) that has 3 options according to the detachment force desired (200, 400, $600 \mathrm{gf})$.

The OLS attachment, on the other hand, has parallel walls and a PEEK retentive matrix with a hole in its center, which apparently doesn't provide the needed resiliency, this may justify the result of the current study ${ }^{[24-26]}$.

\section{CONCLUSION}

Within the limitation of the current study, it could be concluded that resilient matrix (retention sil) for locator attachment induce less bone resorption than peek matrix in anterior grafted mandibular supported bone, however this didn't influence the implant stability.

\section{Financial support and sponsorship:}

Nil.

\section{CONFLICT OF INTEREST}

The authors declare no conflict of interest.

\section{REFERENCES}

1. Evtimovska E., Masri R., Driscoll C.F. and Romberg E.: The change in retentive values of locator attachments and hader clips over time. J. Prosthodont. 18, 479 - 483, 2009.

2. Sadig W.: A comparative in vitro study on the retention and stability of implantsupported overdentures. Quintessence Int, 40, 313- 319, 2009.

3. Nkenke E, Neukam FW. Autogenous bone harvesting and grafting in advanced jaw resorption: morbidity, resorption and implant survival. Eur J Oral Implantol Summer; 7 Suppl 2: S203- 217, 2014.

4. Llambés F, Silvestre FJ, Caffesse R. Vertical guided bone regeneration with bioabsorbable barriers. J Periodontol; 78: 2036 - 2042. 2007.
5. Urban IA, Jovanovic SA, Lozada JL. Vertical ridge augmentation using guided bone regeneration (GBR) in three clinical scenarios prior to implant placement: A retrospective study of 35 patients 12 to 72 months after loading. Int J Oral Maxillofac Implants;24: 502 - 510. 2009.

6. López-Roldán. A, Abad.A, Bertomeu. I, Castillo E, Otaolaurruchi.E. 2Bone resorption processes in patients wearing overdentures, J Clin Exp Dent. 1 (1): e24 - 30, 2009

7. Trakas T, Michalakis K, Kang K, et al: Attachment systems for implant retained overdentures: a literature review. Implant Dent; 15: 24 - 34, 2006.

8. Heckmann SM, Winter W, Meyer M, et al: Overdenture attachment selection and the loading of implant and denture-bearing area. Part 2: A methodical study using five types of attachment. Clin Oral Implants Res; 12: 640 - 647, 2001.

9. Misch CE. Treatment options for mandibular implant overdenture: An organized approach. In: Contemporary implant dentistry, 2nd ed. St. Louis: Mosby; p. 175 - 92. 1998.

10. Walton JN, MacEntee ML. Problems with prostheses on implants: a retrospective study. J Prosthet Dent; 71: 283 - 8, 1994.

11. Ozgun Yusuf Ozyilmaz, Filiz Aykent and Gulsum Sayin Ozel: Effect of mucosa thicknesses on stress distribution of implant-supported overdentures under unilateral loading: Photoelastic analysis Journal of Applied Biomaterials and Functional Material October-December: $1-11$ (C) The Author(s) 2019.

12. Passia, N., Ghazal, M. and Kern, M. Longterm retention behaviour of resin matrix attachment systems for overdentures. Journal of the Mechanical Behavior of Biomedical Materials 57, 88 - 94, 2016.

13. Bayer, S. et al. Retention force of plastic clips on implant bars: A randomized controlled trial. Clinical Oral Implants Research 23, 1377 - 1384, 2012.

14. Mericske-Stern R, Probst D, Fahrlander F, Schellenberg M. Within-subject comparison of two rigid bar designs connecting two interforaminal implants: patients' satisfaction and prosthetic results. Clin Implant Dent Relat Res; 11: 228- 237, 2009. 
15. Geckili O, Bilhan H, Mumcu E, Dayan C, Yabul A, Tuncer N, et al. Comparison of patient satisfaction, quality of life, and bite force between elderly edentulous patients wearing mandibular two implant supported overdentures and conventional complete dentures after 4 years. Spec Care Dentist; 32: 136 41, 2012.

16. Chrcanovic BR, Albrektsson T, Wennerberg A. Reasons for failures of oral implants. J Oral Rehabil; 41: 443 76, 2014.

17. Krennmair $\mathrm{S}$, Weinländer $\mathrm{M}$, Forstner $\mathrm{T}$, Krennmair G, Stimmelmayr M. Factors affecting peri implant bone resorption in four implant supported mandibular full arch restorations: A 3 year prospective study. J Clin Periodontol; 43: 92 101, 2016.

18. Meijer HJ, Raghoebar GM, Van 't Hof MA. Comparison of implant retained mandibular overdentures and conventional complete dentures: A 10 year prospective study of clinical aspects and patient satisfaction. Int $\mathrm{J}$ Oral Maxillofac Implants; 18: 879 85, 2003.

19. Meijer HJ, Kuiper JH, Starmans FJ, Bosman F. Stress distribution around dental implants: influence of superstructure, length of implants, and height of mandible. J Prosthet Dent; 68: 96 - 102. 27, 1992.

20. Zou D, Wu Y, Huang W, A 3-year prospective clinical study of telescopic crown, bar, and locator attachments for removable four implant- supported maxillary overdentures. Int J Prosthodont; 26: 566 - 573. 28, 2013.

21. El-Sheikh AM, Shihabuddin OF, Ghoraba SM. Two versus three narrow-diameter implants with locator attachments supporting mandibular overdentures: a twoyear prospective study. Int J Dent., (5): 285684, 2012.

22. Chikunov I, Doan P, Vahidi F. Implant-retained partial overdenture with resilient attachments. J Prosthodont; 17: 141 - 148, 2008.

23. Celik G, Uludag B. Photoelastic stress analysis of various retention mechanisms on 3-implantretained mandibular overdentures. J Prosthet Dent; 97: 229 - 235, 2007.

24. Elena Preoteasa, Ana-Maria Cristina Tancu, Cristina Teodora Preoteasa Retention.sil as silicone matrices for implant overdenture Carol Davila University of Medicine and Pharmacy, Bucharest, Romania 2014.

25. Tokuhisa, M., Matsushita, Y. and Koyano, K. In vitro study of a mandibular implant overdenture retained with ball, magnet, or bar attachments: comparison of load transfer and denture stability. Int. J. Prosthodont. 16, 128 - 134, 2003.

26. ELsyad, M. A., Omran, A. O. and Fouad, M. M. Strains Around Abutment Teeth with Different Attachments Used for Implant-Assisted Distal Extension Partial Overdentures: An In Vitro Study. J. Prosthodont. 26, $42-47,2017$. 